\title{
Negative pressure wound therapy for closed incisions in orthopedic trauma surgery: a meta-analysis
}

\author{
Cong Wang ${ }^{1 \dagger}$, Yiwen Zhang $^{2 \dagger}$ and Hao Qu ${ }^{1 *}$
}

\begin{abstract}
Background: This meta-analysis was performed to determine the efficacy of negative pressure wound therapy (NPWT) versus conventional wound dressings for closed incisions in orthopedic trauma surgery.

Methods: A systematic search was performed in PubMed, Embase, and the Cochrane Library databases. The outcome measures included deep surgical site infection (SSI), superficial SSI; wound dehiscence and length of hospital stay. Cochrane collaboration's tool and the Newcastle-Ottawa Scale (NOS) were used to evaluate literature qualities. Meta-analysis was performed using RevMan 5.3 software.

Results: A total of 6 studies including 2 randomized controlled trials (RCTs) and 4 cohort studies met our inclusion criteria. NPWT resulted in a significantly lower incidence of deep SSI, superficial SSI, and wound dehiscence than conventional wound dressings. However, no statistically significant difference was found in the length of hospital stay.

Conclusions: NPWT appeared to be an efficient alternative to help prevent SSIs and wound dehiscence on closed incisions in orthopedic trauma surgery. Rational use of NWPT should be based on the presence of patient's condition and risk factors.
\end{abstract}

Keywords: Negative pressure wound therapy, Conventional wound dressings, Surgical site infection, Closed incisions, Orthopaedic trauma, Meta-analysis

\section{Background}

Wound complications within the realm of orthopedic trauma surgery are a major concern. Wound healing is particularly challenging following high-energy trauma, and frequently contribute to postoperative wound dehiscence and surgical site infections (SSIs) $[1,2]$. A prospective randomized clinical trial showed an incidence of almost 19\% SSIs following high risk lower extremity fracture surgery [3]. SSIs are a serious wound complication leading to increased postoperative morbidity, mortality, length of hospital stay, and economic costs [4]. With the development of new techniques and strategies, attempts are made to

\footnotetext{
* Correspondence: email@zju.edu.cn

${ }^{\dagger}$ Cong Wang and Yiwen Zhang were co-first author.

'Department of Orthopaedic Surgery, The Second Affiliated Hospital,

Zhejiang University School of Medicine, Hangzhou 310009, People's Republic of China

Full list of author information is available at the end of the article
}

manipulate the wound healing process, improve healing rates, and lower the incidence of infectious complications. Examples are antibiotic prophylaxis, multiple-dose administration of prophylaxis, less invasive surgical approaches, and prophylactic negative pressure wound therapy (NPWT).

NPWT as an adjunct to wound healing has been developed more than a decade ago [5]. NPWT has 3 main components that create a negative pressure environment: a vacuum device, a porous dressing, and a connector that allows communication. The porous dressing placed on the wound is a dry, hydrophobic, reticulated polyurethane-ether foam. The wound and porous dressing are sealed via an occlusive adhesive dressing, and communicate with the vacuum device via a connector creating a subatmospheric pressure environment. NPWT promotes wound healing by providing wound coverage, reducing dead space and minimizing tension, 


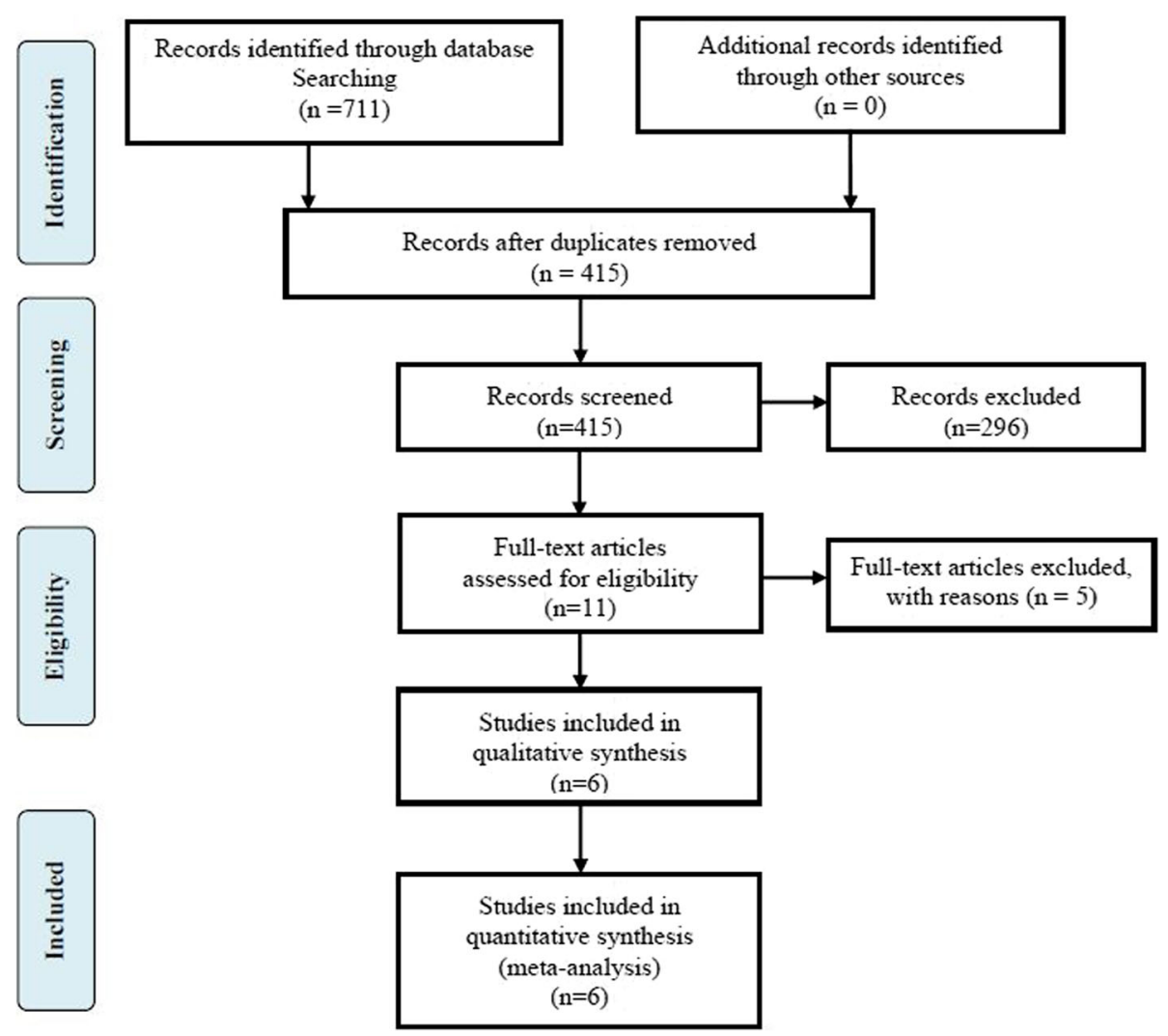

Fig. 1 The flow chart of literature screening

increasing blood flow, reducing edema, and constructing an environment that encourages tissue granulation [68 ]. It has been used successfully in open wound management and wound complications following orthopedic surgery. As orthopedists become more familiar with NPWT, they expanded the application in various surgical procedures; for example, it is now being used as postoperative dressing for fasciotomy wounds after compartment release [9]. Recent studies have showed the application of prophylactic NPWT on closed incisions following high-energy lower extremity trauma and total joint arthroplasty [3,10-12]. These positive results suggest that NPWT may become an adjunct to reduce wound complications for primarily closed incisions in orthopedic trauma surgery, but no clear consensus was achieved based on current researches.

The purpose of this study was to meta-analyze the current evidence in the literature to assess clinical

Table 1 Characteristics of the studies included in the meta-analysis

\begin{tabular}{|c|c|c|c|c|c|c|c|c|c|}
\hline \multirow[t]{2}{*}{ Study(year) } & \multirow{2}{*}{$\begin{array}{l}\text { Study } \\
\text { Design }\end{array}$} & \multicolumn{2}{|c|}{ Sample size } & \multicolumn{2}{|c|}{ Age, mean $\pm S D, y$} & \multirow{2}{*}{$\begin{array}{l}\text { Duration } \\
\text { of NPWT } \\
\text { treatment }\end{array}$} & \multirow{2}{*}{ Type of fracture } & \multirow[t]{2}{*}{ Follow-up } & \multirow[t]{2}{*}{ Outcome measures } \\
\hline & & NPWT & $\begin{array}{l}\text { Conventional } \\
\text { dressings }\end{array}$ & NPWT & $\begin{array}{l}\text { Conventional } \\
\text { dressings }\end{array}$ & & & & \\
\hline $\begin{array}{l}\text { Cooper } \\
(2018)[15]\end{array}$ & RCS & 27 & 40 & $\begin{array}{l}76.3(58- \\
91)\end{array}$ & $73.2(43-91)$ & 7 days & Periprosthetic fracture & 90 days & $\begin{array}{l}\text { Incisional complications, deep SSI, and } \\
\text { reoperations }\end{array}$ \\
\hline $\begin{array}{l}\text { Crist (2017) } \\
{[16]}\end{array}$ & $\mathrm{RCT}$ & 33 & 33 & $\begin{array}{l}44.2(19- \\
87)\end{array}$ & $43.2(18-92)$ & $>2$ days & Acetabular fracture & $\mathrm{Nr}$ & Deep infection \\
\hline $\begin{array}{l}\text { Dingemans } \\
\text { (2018) [17] }\end{array}$ & PCS & 53 & 47 & $\begin{array}{l}43.9 \pm \\
15.6\end{array}$ & $42.2 \pm 14.6$ & 7 days & $\begin{array}{l}\text { Ankle, talus, calcaneus, } \\
\text { mid-foot fracture }\end{array}$ & 2-4 weeks & $\begin{array}{l}\text { Surgical site infection, wound } \\
\text { dehiscence }\end{array}$ \\
\hline $\begin{array}{l}\text { Reddix } \\
(2010)[10]\end{array}$ & RCS & 235 & 66 & $\begin{array}{l}40.2 \\
(11-75)\end{array}$ & $40.4(16-80)$ & 1-3 days & Acetabular fracture & $\begin{array}{l}\text { 16.2months/ } \\
\text { 37.3months }\end{array}$ & $\begin{array}{l}\text { Deep wound infection, wound } \\
\text { dehiscence }\end{array}$ \\
\hline $\begin{array}{l}\text { Stannard } \\
(2012)[3]\end{array}$ & $\mathrm{RCT}$ & 130 & 119 & $\begin{array}{l}43(18- \\
80)\end{array}$ & $43(18-80)$ & $\begin{array}{l}59 h(21- \\
213)\end{array}$ & $\begin{array}{l}\text { Tibial plateau, pilon, and } \\
\text { calcaneus fractures }\end{array}$ & $\mathrm{Nr}$ & $\begin{array}{l}\text { Acute infections, late infections, and } \\
\text { wound dehiscence }\end{array}$ \\
\hline $\begin{array}{l}\text { Zhou (2016) } \\
\text { [18] }\end{array}$ & RCS & 22 & 54 & $\begin{array}{l}59.1 \pm \\
4.3\end{array}$ & $57.2 \pm 6.2$ & 7 days & Ankle fracture & $\mathrm{Nr}$ & $\begin{array}{l}\text { Superficial SSI, deep SSI, length of } \\
\text { hospital stay and hospital costs }\end{array}$ \\
\hline
\end{tabular}


Table 2 Risk of bias assessment of randomized controlled trials

\begin{tabular}{|c|c|c|c|c|c|c|c|}
\hline Study & Randomization & $\begin{array}{l}\text { Allocation } \\
\text { concealment }\end{array}$ & $\begin{array}{l}\text { Blinding of } \\
\text { participants }\end{array}$ & $\begin{array}{l}\text { Blinding of outcome } \\
\text { assessment }\end{array}$ & $\begin{array}{l}\text { Incomplete } \\
\text { outcome data }\end{array}$ & $\begin{array}{l}\text { Selective outcome } \\
\text { reporting }\end{array}$ & $\begin{array}{l}\text { Other } \\
\text { bias }\end{array}$ \\
\hline $\begin{array}{l}\text { Crist (2017) } \\
\text { [16] }\end{array}$ & Low & Unclear & Unclear & Unclear & Low & Low & Unclear \\
\hline $\begin{array}{l}\text { Stannard } \\
(2012)[3]\end{array}$ & Low & Unclear & Unclear & Unclear & Low & Low & Unclear \\
\hline
\end{tabular}

results of NPWT versus conventional wound dressings for closed incisions in orthopedic trauma surgery. The hypothesis was that NPWT would result in less SSIs and wound dehiscence when compared with conventional wound dressings.

\section{Methods}

Literature search

Two independent reviewers performed this study according to the PRISMA (Preferred Reporting Items for Systematic Reviews and Meta-Analyses) guidelines. The electronic databases of PubMed, Embase, and the Cochrane Library databases were searched from the inception of the database to November 1, 2019. The following search terms was used: (negative pressure wound therapy or negative pressure dressings or vsd or vacuum sealing drainage or vacuum-assisted closure) and (fracture or orthopedic trauma) and incision. The title and abstract were screened for all retrieved citations, and potentially suitable studies received a full-text review. Furthermore, the reference lists from included articles and relevant reviews were assessed to identify additional studies meeting the inclusion criteria.

\section{Inclusion and exclusion criteria}

We identified literature that met the following inclusion criteria: (1) clinical studies comparing NPWT versus conventional wound dressings for closed incisions in orthopedic trauma surgery, including randomized control trials (RCTs), cohort studies, and case-control studies; (2) published in English; (3) outcomes including the incidence of SSIs; and (4) full text of studies available. The exclusion criteria were the following: (1) abstract, letters, editorials, conference articles, case reports, reviews, animal studies, and study protocols, (2) repeated studies and data.

Table 3 Quality assessment according to the Newcastle-Ottawa scale

\begin{tabular}{lllll}
\hline Study & Selection & Comparability & Exposure & Total score \\
\hline Cooper (2018) [15] & 3 & 2 & 3 & 8 \\
Dingemans (2018) [17] & 3 & 2 & 2 & 7 \\
Reddix (2010) [10] & 3 & 1 & 3 & 7 \\
Zhou (2016) [18] & 3 & 2 & 2 & 7 \\
\hline
\end{tabular}

\section{Data extraction}

Two reviewers independently extracted the data from each study using a predefined data sheet, relevant data extracted included first author, year of publication, study design, sample size, age, duration of NPWT treatment, type of fracture, follow-up, and outcome measures. Whenever necessary, we contacted the authors of the studies for the missing data and additional information.

\section{Assessment of study quality}

The methodological quality assessment of the included RCTs was independently assessed by two reviewers using the Cochrane collaboration's tool [13]. The risk of bias was classified as low, unclear, or high risk. The methodological quality of included cohort studies was assessed according to the Newcastle-Ottawa Scale (NOS) [14]. The NOS uses a star system ranges from zero to nine stars. Studies of high quality were defined as those with scores higher than 6 stars.

\section{Outcomes measured}

The outcomes measured focused on (1) deep SSI; (2) superficial SSI; (3) wound dehiscence; (4) length of hospital stay.

\section{Statistical analysis}

Statistical analysis was performed using RevMan 5.3 for outcome measurements. The estimate of the overall results was showed in forest plot. Odds ratios (OR) with 95\% confidence interval (95\% CI) were calculated for dichotomous outcomes, and mean difference (MD) with 95\% CI were used for continuous outcomes. Heterogeneity among studies was tested using $I^{2}$ statistic, and substantial heterogeneity was represented by an $I^{2}$ value greater than $50 \%$. If significant heterogeneity was found in the meta-analysis, we used a random effect model; otherwise, we used a fixed effect model. $P$ value less than 0.05 was considered to be statistically significant.

\section{Results}

\section{Literature search}

The initial electronic databases search yielded 711 relevant articles. Manual searching of relevant references did not add additional studies. After both duplicate checking and title and abstract reviewing, 700 studies were excluded. The remaining 11 studies were subjected to full-text screen. Ultimately, two RCTs and four cohort 


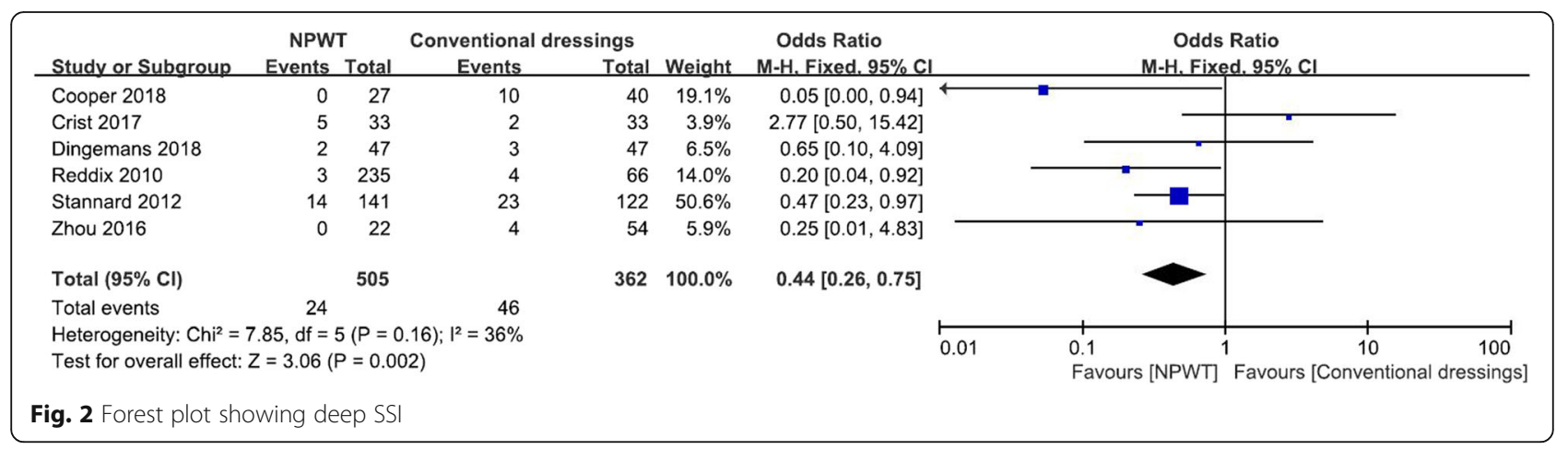

trials were eligible for meta-analysis [3, 10, 15-18]. A flowchart of the literature search is shown in Fig. 1.

\section{Characteristics and quality assessment of the eligible studies}

The characteristics of the six included studies are listed in Table 1. The studies were published between 2010 and 2018. The two RCTs and four cohort trials involved a total of 859 patients. A total of 500 patients used NPWT after the surgeries, whereas 359 applied conventional wound dressings. A great majority of the included patients suffered from low extremity and acetabular fractures. The risk of bias assessment of two RCTs are illustrated in Table 2. The methodological quality of four cohort trials assessed with the NOS are shown in Table 3.

\section{Deep SSI}

Deep SSIs were reported in 6 studies [3, 10, 15-18], with 505 NPWT and 362 conventional wound dressings. The NPWT resulted in $4.8 \%$ of patients having deep SSIs, compared with conventional wound dressings where $12.7 \%$ of patients had deep SSIs. There was a statistically significant difference in favor of the NPWT (OR, 0.44; 95\% CI, 0.26-0.75; $I^{2}=36 \% ; P=0.002$; Fig. 2).

\section{Superficial SSI}

Superficial SSIs were reported in 2 studies [17, 18], with 69 NPWT and 101 conventional wound dressings. The NPWT resulted in $1.4 \%$ of patients having superficial SSIs, compared with conventional wound dressings where $14.9 \%$ of patients had superficial SSIs. There was a statistically significant difference in favor of the NPWT (OR, 0.15; 95\% CI, 0.03-0.84; $I^{2}=0 \% ; P=0.03$; Fig. 3).

\section{Wound dehiscence}

Wound dehiscence was reported in 2 studies [3, 10], with 376 NPWT and 188 conventional wound dressings. The NPWT resulted in $3.5 \%$ of patients having wound dehiscence, compared with conventional wound dressings where $11.7 \%$ of patients had wound dehiscence. There was a statistically significant difference in favor of the NPWT (OR, 0.43; 95\% CI, 0.21-0.88; $I^{2}=0 \% ; P=$ 0.02; Fig. 4).

\section{Length of hospital stay}

Length of hospital stay was reported in 3 studies $[15,16$, 18], comprising 82 NPWT and 127 conventional wound dressings. The NPWT resulted in a mean length of hospital stay of 10.65 days, compared with the conventional wound dressings where mean length of hospital stay was 11.78 days. There was no statistically significant difference between the techniques (MD, - 0.49; 95\% CI, 2.96-1.99; $I^{2}=90 \% ; P=0.7$; Fig. 5).

\section{Discussion}

The successful use of NPWT on open wound management led some orthopedists to expand the application of NPWT for some closed incisions. A recent consensus panel recommended the use of NPWT on patients who are at high risk of postoperative wound complications [19]; however, these recommendations have been

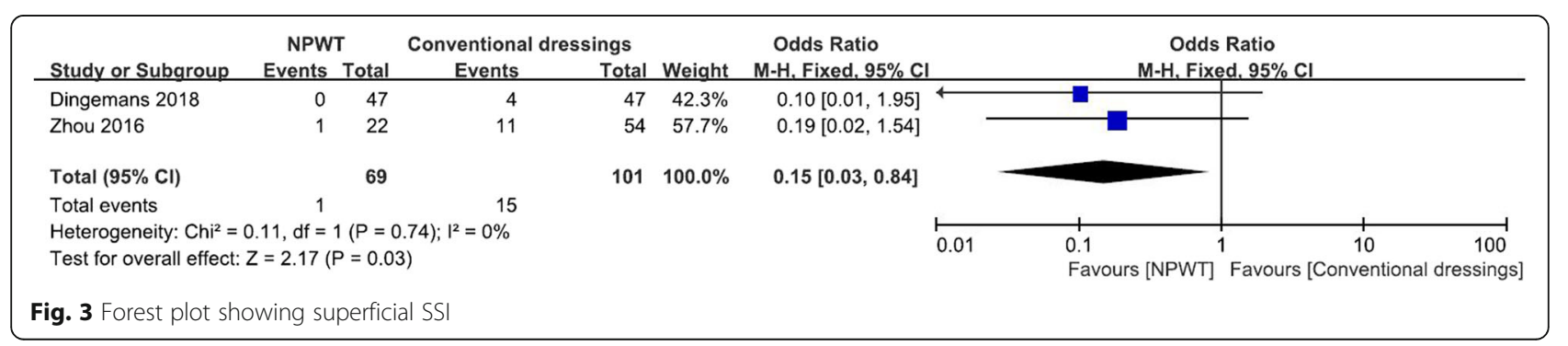




\begin{tabular}{|c|c|c|c|c|c|c|c|c|c|c|}
\hline Study or Subaroup & \multicolumn{2}{|c|}{$\begin{array}{l}\text { NPWT } \\
\text { Events Total }\end{array}$} & \multicolumn{2}{|c|}{ Conventional dressings } & Weight & \multirow{2}{*}{$\begin{array}{l}\begin{array}{c}\text { Odds Ratio } \\
\text { M-H. Fixed. } 95 \% \text { Cl }\end{array} \\
0.14[0.01,1.53]\end{array}$} & \multicolumn{4}{|c|}{$\begin{array}{c}\text { Odds Ratio } \\
\text { M-H. Fixed. 95\% Cl }\end{array}$} \\
\hline Reddix 2010 & 1 & 235 & 2 & 66 & $13.7 \%$ & & & & & \\
\hline Stannard 2012 & 12 & 141 & 20 & 122 & $86.3 \%$ & $0.47[0.22,1.02]$ & & & & \\
\hline Total $(95 \% \mathrm{Cl})$ & & 376 & & 188 & $100.0 \%$ & $0.43[0.21,0.88]$ & & & & \\
\hline Total events & 13 & & 22 & & & & & & & \\
\hline $\begin{array}{l}\text { Heterogeneity: } \mathrm{Chi}^{2}= \\
\text { Test for overall effect }\end{array}$ & $\begin{array}{l}.93, \mathrm{df}= \\
=2.29(f\end{array}$ & $\begin{array}{l}(P=0 \\
=0.02\end{array}$ & 2) & & & & 0.01 & $\begin{array}{ll}0.1 & 1 \\
\text { Favours [NPWT] }\end{array}$ & 1 Favours [C & $\begin{array}{cc}10 & 100 \\
\text { nnventional dressings] }\end{array}$ \\
\hline
\end{tabular}

challenged by the results of more recent studies in orthopedic trauma $[16,17]$. Therefore, we performed this meta-analysis to compare NPWT and conventional wound dressings for closed incisions in orthopedic trauma surgery. The most important finding of present meta-analysis was that NPWT significantly reduced the incidence of deep SSI, superficial SSI, and wound dehiscence, and no increased length of hospital stay was identified.

Regarding the wound complications, previous systematic review and meta-analysis showed that NPWT can reduce the risk of infection of the patients in treatment of open fractures and accelerate the wound healing process [20]. In open wounds, NPWT promotes wound healing by facilitating removal of excess interstitial fluid, reducing edema, enhancing tissue growth, and expansion $[6,8]$. In closed incisions, NPWT functions to promote drainage, improve lymphatic flow, decrease hematoma, and seroma formation, and it reduces relative motion at the surgical site and decreases lateral tension across the incision line [21-23]. Recent clinical studies suggest that NPWT can be a prophylactic treatment to decrease the incidence of infection in high-risk patients following lower extremity fractures as well as following total joint arthroplasty [24, 25]. Consistently, the present metaanalysis indicated that NPWT significantly reduced the incidence of deep surgical site infection, superficial surgical site infection, and wound dehiscence on closed incisions in orthopedic trauma surgery. However, there was no statistically significant difference in the length of hospital stay. For wound, complication is not the only determinant. The duration of NPWT treatment may also influence the hospital stay. And the sample size may be too small to reflect significant difference between the groups.

An obvious and important advantage of NPWT is that it needs less dressing changes compared with conventional wound dressings. NPWT reduces the strain on doctor and nursing staff, and it is particularly obvious in obese patients or in special wound locations, such as the popliteal fossa, buttocks, or groin. To some extent, use of NPWT is beneficial in the prevention of wound infection as each dressing change is a potential opportunity of contamination of the wound. Therefore, NPWT is suitable for the patients who are sent to the intensive care unit during the immediate postoperative period. Furthermore, patients were satisfied with the NPWT as it provides a cleaner wound environment, and they did not have to take care of the surgical incision.

In current modern healthcare environment, it is also important to consider the economic factors when we make treatment decisions. The costs of NPWT have been estimated to be less than $\$ 500$ per patient [3], but the health care costs associated with postoperative SSIs can be enormous [26, 27]. Therefore, in patients at high risk for wound complications, it would be reasonable and cost-effective to use NPWT for closed incisions in orthopedic trauma surgery. Furthermore, the use of NPWT did not increased the length of hospital stay.

Although the current application of NPWT for closed incisions in orthopedic trauma surgery has yielded some satisfactory results, it does not mean that NPWT should be used for all orthopedic trauma surgeries. Rational use of NWPT should be based on the presence of patient's condition and risk factors [19]. The fractures involved in present study are calcaneus, pilon, ankle, tibial plateau,

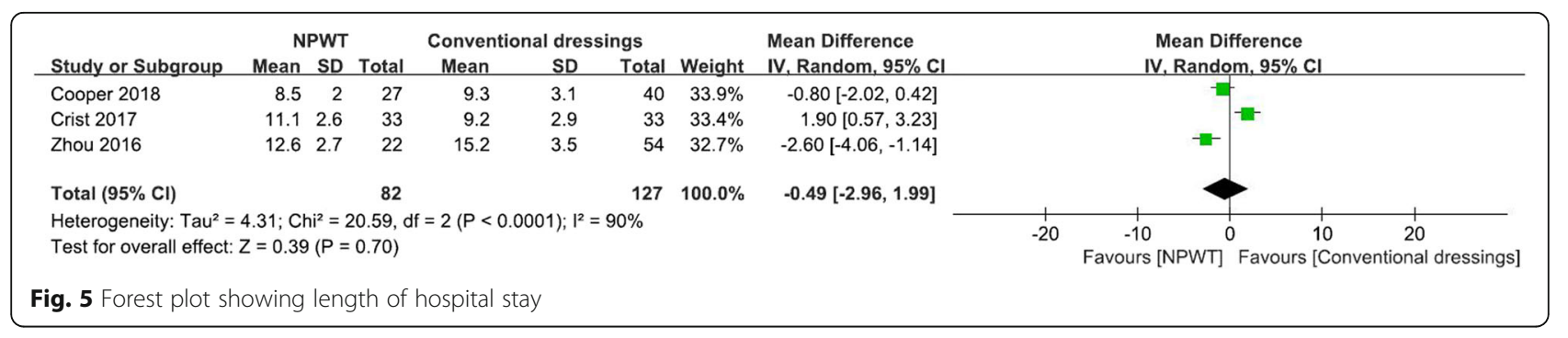


and acetabular fractures, which are frequently accompanied with high likelihood of prolonged wound drainage and postoperative wound swelling [11]. Those patients are at a high risk of SSIs and soft tissue healing problems after the surgeries. And this problem is further aggravated if the patient has the most common patientrelated risk factors, including obesity, diabetes mellitus, tobacco use, and prolonged surgical time [28-31]. Therefore, it is reasonable that current study obtained the positive results about the use of NPWT for closed incisions. It is important to note that study to support its widespread application in all cases in orthopedic trauma surgery is lacking, large, and well-designed RCTs are needed in the future to validate the efficacy and safety of NPWT.

Nonetheless, some limitations in the present metaanalysis should be noted. (1) Only four cohort studies and two RCTs were included in the present metaanalysis, and the sample size was relatively small, which might lower the evidence level. (2) The duration of NPWT treatment of the included studies were inconsistent. (3) The fractures involved in present study are lower extremity and acetabular fractures, which are at a high risk of infection, and soft tissue healing problems after surgeries, so the outcome should be treated cautiously.

\section{Conclusion}

In conclusion, NPWT appeared to be an efficient alternative to help prevent SSIs and wound dehiscence on closed incisions in orthopedic trauma surgery. Rational use of NWPT should be based on the presence of patient's condition and risk factors. More large multicenter and high-quality RCTs are required for further research [32].

\section{Abbreviations}

Cl: Confidence interval; MD: Mean difference; NOS: Newcastle-Ottawa Scale; NPWT: Negative pressure wound therapy; OR: Odds ratios; RCTs: Randomized controlled trials; SSI: Surgical site infection

\section{Acknowledgements}

None.

\section{Authors' contributions}

CW contributed to the conception and design of the study. YWZ and CW participated in the literature search, study selection, data extraction, and quality assessment. YWZ and CW performed the statistical analysis and drafted the manuscript. HQ contributed to the revisions of the manuscript. All authors read and approved the final manuscript.

\section{Funding}

This work was supported by Zhejiang Province Natural Science Foundation of China [Grant NO. LQ19H060003].

\section{Availability of data and materials}

All data generated or analyzed during this study are included in published articles.

Ethics approval and consent to participate

Not applicable.
Consent for publication

Not applicable.

\section{Competing interests}

The authors declare that they have no competing interests.

\section{Author details}

${ }^{1}$ Department of Orthopaedic Surgery, The Second Affiliated Hospital,

Zhejiang University School of Medicine, Hangzhou 310009, People's Republic of China. ${ }^{2}$ Operating Room, The Second Affiliated Hospital, Zhejiang

University School of Medicine, Hangzhou 310009, People's Republic of China.

Received: 14 October 2019 Accepted: 26 November 2019

Published online: 11 December 2019

\section{References}

1. McFerran MA, Smith SW, Boulas HJ, et al. Complications encountered in the treatment of pilon fractures. J Orthop Trauma. 1992;6:195-200.

2. Benirschke SK, Kramer PA. Wound healing complications in closed and open calcaneal fractures. J Orthop Trauma. 2004;18:1-6.

3. Stannard JP, Volgas DA. McGwinG et al. Incisional negative pressure wound therapy after high-risk lower extremity fractures. J Orthop Trauma. 2012; 26(1):37-42

4. Whitehouse J, Friedman N. The impact of surgical-site infections following orthopedic surgery at a community hospital and a university hospital: adverse quality of life, excess length of stay. Infect Control Hosp Epidemiol. 2002;23(4):183-9.

5. Semsarzadeh NN, Tadisina KK, Maddox J, Chopra K, Singh DP. Closed incision negative-pressure therapy is associated with decreased surgical site infections: a meta-analysis. Plast Reconstr Surg. 2015;136:592-602.

6. Suzuki T, Minehara A, Matsuura T, Kawamura T, Soma K. Negative-pressure wound therapy over surgically closed wounds in open fractures. J Orthop Surg (Hong Kong). 2014;22(1):30-4

7. Stannard JP, Singanamala N, Volgas DA. Fix and flap in the era of vacuum suction devices: what do we know in terms of evidence based medicine? Injury. 2010;41(8):780-6.

8. Morykwas MJ, Argenta LC, Shelton-Brown El, McGuirt W. Vacuum-assisted closure: a new method for wound control and treatment: animal studies and basic foundation. Ann Plast Surg. 1997;38(6):553-62.

9. Yang CC, Chang DS, Webb LX. Vacuum-assisted closure for fasciotomy wounds following compartment syndrome of the leg. J Surg Orthop Adv. 2006;15(1):19-23.

10. Reddix RN Jr, Leng XI, Woodall J, Jackson B, Dedmond B, Webb LX. The effect of incisional negative pressure therapy on wound complications after acetabular fracture surgery. J Surg Orthop Adv. 2010;19:91-7.

11. Gomoll AH, Lin A, Harris MB. Incisional vacuum-assisted closure therapy. J Orthop Trauma. 2006;20:705-9.

12. Cooper HJ, Bas MA. Closed-incision negative-pressure therapy versus antimicrobial dressings after revision hip and knee surgery: a comparative study. J Arthroplasty. 2016;31:1047-52.

13. Higgins JP, Green S, Collaboration C. Cochrane Handbook for Systematic Reviews of Interventions 5: Wiley Online Library; 2008.

14. Wells GA, Shea B, O'Connell D, Peterson J, Welch V, Losos M. The Newcastle-Ottawa Scale (NOS) for assessing the quality of non-randomized studies in meta-analysis. Ottawa Health Research Institute. Available from: http://www.ohri.ca/programs/clinical_epidemiology/oxford.asp. (Accessed 20 Aug 2019)

15. Cooper HJ, Roc GC, Bas MA, Berliner ZP, Hepinstall MS, Rodriguez JA, Weiner LS. Closed incision negative pressure therapy decreases complications after periprosthetic fracture surgery around the hip and knee. Injury. 2018;49(2): 386-91.

16. Crist BD, Oladeji LO, Khazzam M, Della Rocca GJ, Murtha YM, Stannard JP. Role of acute negative pressure wound therapy over primarily closed surgical incisions in acetabular fracture ORIF: a prospective randomized trial. Injury. 2017;48(7):1518-21.

17. Dingemans SA, Birnie MFN, Backes M, de Jong VM, Luitse JS, Goslings JS, Schepers T. Prophylactic negative pressure wound therapy after lower extremity fracture surgery: a pilot study. Int Orthop. 2018:42(4):747-53

18. Zhou ZY, Liu YK, Chen HL, Liu F. Prevention of surgical site infection after ankle surgery using vacuum-assisted closure therapy in high-risk patients with diabetes. J Foot Ankle Surg. 2016;55(1):129-31. 
19. Willy C, Agarwal A, Anderson CA, et al. Closed incision negative pressure therapy: international multidisciplinary consensus recommendations. Int Wound J. 2017;14:385-98.

20. Liu X, Zhang H, Cen S, Huang F. Negative pressure wound therapy versus conventional wound dressings in treatment of open fractures: a systematic review and meta-analysis. Int J Surg. 2018;53:72-9.

21. Kilpadi DV, Cunningham MR. Evaluation of closed incision management with negative pressure wound therapy (CIM): hematoma/seroma and involvement of the lymphatic system. Wound Repair Regen. 2011;19:588-96.

22. Pachowsky M, Gusinde J, Klein A, Lehrl S, Schulz-Drost S, Schlechtweg P, et al. Negative pressure wound therapy to prevent seromas and treat surgical incisions after total hip arthroplasty. Int Orthop. 2012;36:719-22.

23. Wilkes RP, Kilpad DV, Zhao Y, Kazala R, McNulty A. Closed incision management with negative pressure wound therapy (CIM): biomechanics. Surg Innov. 2012;19:67-75.

24. Brem MH, Bail HJ, Biber R. Value of incisional negative pressure wound therapy in orthopaedic surgery. Int Wound J. 2014;11(Suppl 1):3-5.

25. Kim JH, Kim HJ, Lee DH. Comparison of the efficacy between closed incisional negative-pressure wound therapy and conventional wound management after total hip and knee arthroplasties: a systematic review and meta-analysis. J Arthroplasty. 2019.

26. de Lissovoy G, Fraeman K, Hutchins V, et al. Surgical site infection: incidence and impact on hospital utilization and treatment costs. Am J Infect Control. 2009;37:387-97.

27. Zimlichman E, Henderson D, Tamir O, et al. Health careassociated infections: a meta-analysis of costs and financial impact on the US health care system. JAMA Intern Med. 2013;173:2039-46.

28. Jain RK, Shukla R, Singh P, et al. Epidemiology and risk factors for surgical site infections in patients requiring orthopedic surgery. Eur J Orthop Surg Traumatol. 2015;25:251-4.

29. Li GQ, Guo FF, Ou Y, et al. Epidemiology and outcomes of surgical site infections following orthopedic surgery. Am J Infect Control. 2013:41:1268-71.

30. Richards JE, Kauffmann RM, Zuckerman SL, et al. Relationship of hyperglycemia and surgical-site infection in orthopaedic surgery. J Bone Joint Surg Am. 2012;94:1181-6.

31. Sagi HC, Dziadosz D, Mir H, et al. Obesity, leukocytosis, embolization, and injury severity increase the risk for deep postoperative wound infection after pelvic and acetabular surgery. J Orthop Trauma. 2013;27:6-10.

32. Knight R, Spoors LM, Costa ML, Dutton SJ. Wound Healing In Surgery for Trauma (WHIST): statistical analysis plan for a randomised controlled trial comparing standard wound management with negative pressure wound therapy. Trials. 2019;20(1):186.

\section{Publisher's Note}

Springer Nature remains neutral with regard to jurisdictional claims in published maps and institutional affiliations.

Ready to submit your research? Choose BMC and benefit from:

- fast, convenient online submission

- thorough peer review by experienced researchers in your field

- rapid publication on acceptance

- support for research data, including large and complex data types

- gold Open Access which fosters wider collaboration and increased citations

- maximum visibility for your research: over $100 \mathrm{M}$ website views per year

At $\mathrm{BMC}$, research is always in progress.

Learn more biomedcentral.com/submissions 